Automation and Robotics in Construction $\mathrm{X}$

G.H. Watson, R.L. Tucker and J.K. Walters (Editors)

¿ iуyj Eisevier Science Publishers B.V. All rights reserved.

\title{
An Evaluation of the Pipe Manipulator Performance in a Material Handling Yard
}

\author{
Hsieh, T.Y., Research Assistant \\ Fulton, C., Research Assistant \\ Dr. Gibson, G. E. Assistant Professor \\ Dr. Haas, C.T., Assistant Professor \\ Department of Civil Engineering \\ University of Texas at Austin \\ Austin, Texas 78712, USA
}

\begin{abstract}
The purpose of this paper is to compare the productivity between a prototype pipe manipulator and a telescopic rough-terrain crane in handling pipes in a piping material laydown yard. Productivity data were collected by video-taping identical operations performed by the two machines in the field. The productivity data are evaluated in terms of the total cycle time and total work-hours. The results show that the pipe manipulator has a slightly shorter cycle time but is outperformed by a cherry picker by a ratio of $5.16: 1$ in terms of total work-hours, primarily due to the gripper's restriction on lifting one pipe per lift. A discussion of the possible ways to improve the manipulator's productivity in handling pipes reveals two major directions for enhancements: (1) enabling multi-pipe lift and (2) designing a better control system. These enhancements not only augment the manipulator's productivity to be comparative to that of a cherry picker but also reduce the cycle time by $67 \%$.
\end{abstract}

\section{INTRODUCTION}

This paper describes the research results of one facet of a larger ongoing research program being conducted at the University of Texas at Austin [7,8]. This research program centers on the issues of developing a large-scale manipulator for construction use. A prototype manipulator, the Grove Pipe Manipulator, is being used as a test bed for various types of experiments. The physical characteristics of the pipe manipulator have been extensively discussed in previous literature $[1,2,4,5]$. The focus of this paper is in evaluating the productivity of the Pipe Manipulator in handling pipes in a piping material laydown yard versus that of a conventional mobile telescopic crane (cherry picker). It was also recognized that this prototype manipulator can benefit workers' safety to a great extent. However, this aspect will not be discussed in more depth within this context.

This research involves the use of a video camera to record and analyze the productivity data of both machines. Approximately sixty minutes of pipe handling operations were filmed. The productivity data were then recorded manually by replaying the tape. To verify the collected data and gain more insight, formal and informal interviews were conducted. All the productivity data comparisons are based on identical operations with the same size and length of pipes.

The paper first introduces the current practice of pipe handling in a laydown yard. Then, the acquired productivity data are displayed. In data analysis, thorough discussions are provided surrounding the issue of productivity comparison with varying factors. An extension of effort is made in the following section in predicting the potential productivity improvement on the Pipe Manipulator should some enhancements be made. Finally, conclusions are given regarding the significance of the research findlings. 


\section{CURRENT OPERATIONS OF PIPE HANDLING IN A LAYDOWN YARD}

The standard pipe length delivered to material laydown yard is typically 40 feet. This extended length, as opposed to a shorter length of $20 \mathrm{feet}$, reduces the number of welds required of the construction contractors during assembly operations. With this 40 foot length, the current pipe unloading operation requires a crew of five: one cherry picker operator, two riggers on the flatbed, and two workers on the ground for pipe control and placement.

The sequence of operation is as follows. Suppliers deliver one size and type of pipe on standard flatbed delivery trucks in several stacked configurations including:

(1) Pipe stacked into a pyramid formation with no spacers between the layers, and with pipe resting on pipe.

(2) Pipe stacked in layers with wood spacers separating each layer.

(3) Large pipe placed in a single layer, resting on the flatbed.

(4) Smaller pipe in bundles, with metal bands holding the pipe together.

In mest situations, standard hold-down chains or nylon straps are used to secure the load while in transit. Also, when pipe is delivered in a stacked configuration, flatbed side stakes are often employed to arrest any lateral motion of the pipe. The configuration of pipe delivery, and the weight of the pipe will influence the type of rigging to be employed during offloading.

From field observations and interviews, several factors which will influence the positioning of the crane relative to the delivery truck during offloading operations were identified and include:

(1) Maneuvering room for the delivery truck.

(2) Space available to position the crane relative to the truck.

(3) Orientation of the pipe on the ground.

(4) Space available to traverse the pipe from truck to ground.

(5) Weight of the pipe.

Consequently, the goals of handling pipes by a cherry picker are to: (1) reduce the movement of the boom while unloading; (2) reduce the horizontal extension of the boom for stability reasons; and (3) reduce the distance required to move the pipe. The reduction in movement of equipment and material can result in higher proluctivity. This aspect, however, will not be explored further in this paper.

\section{DATA ACQUISITION}

Two techniques were used to gather data on the equipment's performance: (1) Field tests were videotaped using a standard portable video cassette recorder; and (2) Formal and informal interviews of management and field personnel were conducted. The goal of filming was to record the cherry picker and the pipe manipulator performing identical operations so that an accurate comparison of their performance and productivity could be obtained.

The drawback of a standard VCR is that analysis of the tape is much more tedious and time consuming compared to other methods such as time-lapse film. Time-lapse film can be viewed at a multitude of speeds such that an 8 hour work dily can be viewed in as little as one hour, while VCR analysis requires the full 8 hours to review. Nevertheless, because the total recording time is less than one hour in this study, this drawback does not impose any particular difficulty.

A typical pipe handling operation of a cherry picker involves three major steps, namely, attaching sling, lifting and placing, and detaching sling and returning to the original position. In this analysis, six cycles of pipe handling operation were recorded, as shown in Table 1. 
Table 1 Productivity Data for Cherry Picker (in seconds)

\begin{tabular}{lcccc}
\hline & Rig Load & Lift and Place & Unrig and Return & Total Time \\
\hline Cycle \#1 & 101 & 68 & 65 & 234 \\
Cycle \#2 & 75 & 50 & 40 & 165 \\
Cycle \#3 & 30 & 45 & 60 & 135 \\
Cycle \#4 & 125 & 55 & 45 & 225 \\
Cycle \#5 & 140 & 110 & 45 & 295 \\
Cycle \#6 & 30 & 55 & 50 & 135 \\
\hline Average Time & 84 & 64 & 51 & 198 \\
\hline
\end{tabular}

A typical manipulator operation can also be divided into three major steps. The "Grasping" involves the motions of approaching the pipe and the actual gripping. The "Lift and Move" consists of lifting the pipe off the flatbed, swinging and placing the pipe to the designated yard location. Finally, the "Release \& Return" represents the motions of releasing the pipe from the control of the gripper and moving the gripper back to the arrays of pipe. This fashion of motion classification results in the convenience of recording productivity data from VCR reviews. The manipulator productivity data are shown in Table 2.

Table 2 Productivity Data for Pipe Manipulator (in seconds)

\begin{tabular}{lcccc}
\hline & Grasping & Lift \& Move & Release \& Return & Total Time \\
\hline Cycle \#1 & 25 & 70 & 49 & 144 \\
Cycle \#2 & 41 & 90 & 50 & 181 \\
Cycle \#3 & 22 & 80 & 42 & 166 \\
Cycle \#4 & 30 & 81 & 40 & 151 \\
Cycle \#5 & 40 & 81 & 61 & 185 \\
Cycle \#6 & 40 & 139 & 55 & 155 \\
Cycle \#7 & 40 & 60 & 64 & 243 \\
Cycle \#8 & 23 & 69 & 73 & 165 \\
Cycle \#9 & 10 & 49 & 51 & 110 \\
Cycle \#10 & 21 & 96 & 58 & 175 \\
Cycle\#11 & 63 & 56 & 55 & 174 \\
\hline Average Time & 32 & 79 & 54 & 165 \\
\hline
\end{tabular}

\section{DATA ANALYSIS}

From Tables 1 and 2, it can be seen that, in terms of the completion time per lift cycle, the Pipe Manipulator outperforms the Cherry Picker by a ratio of $1.2: 1$. It is felt that this difference of performance is marginal and may well be balinced out by the experimental errors introduced by the research method.

In addition to total completion time, two other factors need to be used in comparing their performance. Because of the difference in physical capabilities, these two machines work with different sizes of crews and can handle different number of pipes per lift. In the field experiment, the crew size for the Cherry Picker was tive, whereas the manipulator has only one, the operator. However, the Cherry Picker can handle 31 pieces of pipe in one lift when they are bundled together, white only one pipe can be handied by the manipulator per lift. With this infornation, the productivity of both machines is presented in Table 3.

Table 3 Productivity Comparisons

\begin{tabular}{cccccc}
\hline & Crew Size & \# of Pipe/Lift & Time/Lift & Man-Sec/Lift & Man-Sec/Pipe \\
\hline Manipulator & 1 & 1 & 16.5 & 16.5 & 165 \\
Cherry Picker & 5 & 31 & 198 & 990 & 32 \\
\hline Ratio (M/C) & 0.2 & 0.03 & 0.83 & 0.17 & 5.16 \\
\hline
\end{tabular}


"Man-Second per Pipe" is a productivity criterion that is closely related to labor costs. Since the cycle completion time of both machines is comparative, the productivity based on this criterion is determined by the number of pipes per lift and the crew size. From Table 3, it is clear that the productivity of the Pipe Manipulator is critically undermined by its limitation of handling one pipe at a time, although the Cherry Picker requires a crew of five.

Understandably, the observations from the field experiment may not reflect all possible configuration of a pipe handling operation performed by a cherry picker and a manipulator. Under other circumstances such as longer or larger pipes to be handled and the congestion of the laydown yard, both the number of pipes to be handled per lift and the crew size may vary. Consequently, the study results derived thus far may not provide enough insight. To grasp the dynamics of many "what-if" conditions, it is useful to establish the relationship of productivity on both machines as follows:

Proxuctivity $=$ Cycle Time $* \frac{\text { No. Pipes Handled per Lift }}{\text { Crew Size }}$

Assume Productivity cherry picker = Productivity pipe manipulator

Thus, $165 * \frac{\mathrm{P}_{\mathrm{m}}}{\mathrm{C}_{\mathrm{m}}}=198 * \frac{\mathrm{P}_{\mathrm{c}}}{\mathrm{C}_{\mathrm{c}}}$ or $\frac{\mathrm{P}_{\mathrm{c}}}{\mathrm{P}_{\mathrm{m}}}=\frac{165}{198} * \frac{\mathrm{C}_{\mathrm{c}}}{\mathrm{C}_{\mathrm{m}}}$

Where,

$$
\begin{aligned}
& P_{m}: \text { Number of Pipes Handled per Lift by Manipulator } \\
& C_{m}: \text { Crew Size of Manipulator } \\
& P_{c}: \text { Number of Pipes Handled per Lift by Cherry Picker } \\
& C_{c}: \text { Crew Size of Cherry Picker }
\end{aligned}
$$

With this relationship, the sensitivity analysis regarding the variations of the two variables is performed and shown in Figure 3. From Figure 3, the vertical axis, the capacity ratio, represents the ratio between the number of pipes that can be handled per lift by a cherry picker and that by a manipulator. The horizontal axis, the crew size ratio, represents the ratio between the sizes of a cherry picker crew and a manipulator crew. The "Cherry Picker Region" indicates that a cherry picker will be more productive in handling pipes in terms of total work-hours with any given combination of the two ratios in this region.

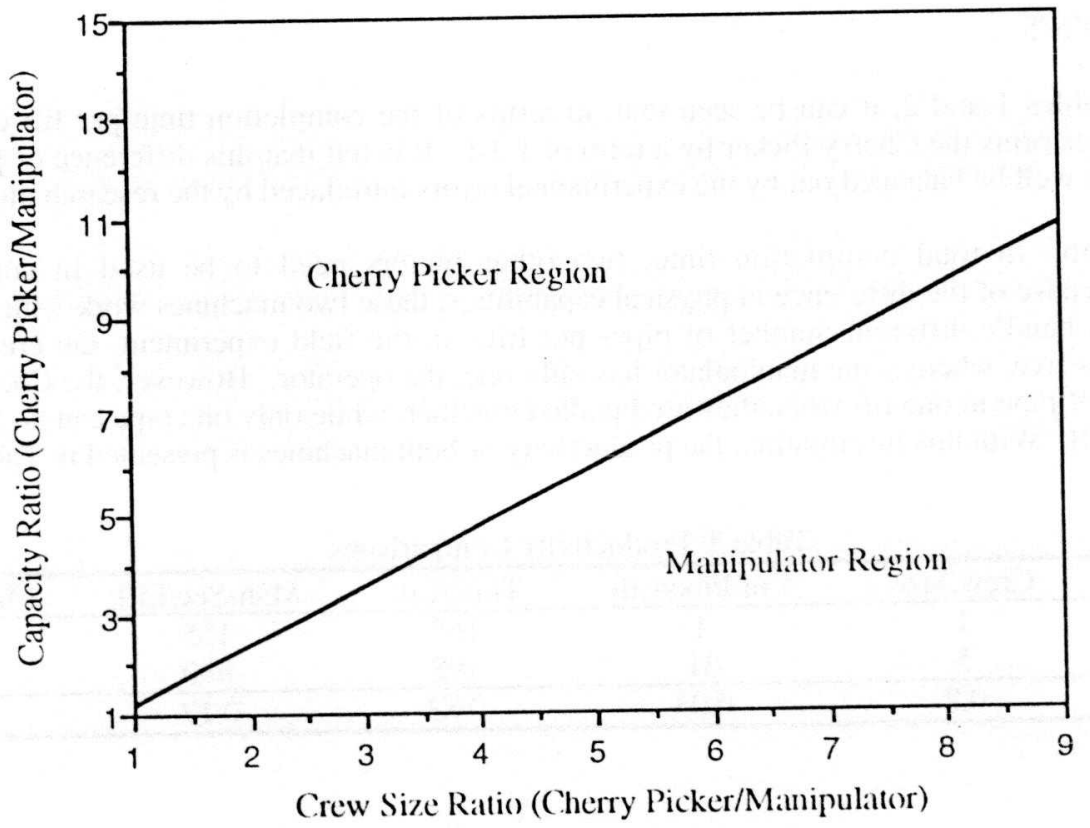

Figure 3 Two-Way Sensitivity Analysis 
According to the field data, the crew size ratio between the two machines is 5 and the capacity ratio is 31. It is not difficult to see that the productivity gap between them are significant. It is also apparent that, given that the cherry picker's crew size is fixed at 5 and the the crew size of the manipulator at 1 , one possible way for the manipulator to compete with the cherry picker is by decreasing the capacity ratio. In this case, the minimal attractive capacity ratio is 6 . In other words, the manipulator would have to handle five pipes per lift to become competitive. Another possible way is to change the linear relationship between the completion times per lift. By so doing, the area of the "Manipulator Region" will increase. The next section discusses these aspects.

\section{DISCUSSION}

From the previous analyses, it is quite clear that constructors will most likely be satisfied with using conventional cherry pickers. In terms of handling pipes in a laydown yard, the major drawbacks or weaknesses of the pipe manipulator can be summarized as follows:

(1) Its lifting capacity is limited to 1600$)$ pounds, whereas a cherry picker has a capacity of 20,000 pounds (12.5 times);

(2) The gripper can only handle one pipe per lift resulting in a high capacity ratio; and

With the current control system, the operator can only move one joint at a time, resulting in a longer operation time.

As mentioned earlier, to improve the productivity of the manipulator, two major aspects need to be considered. The first is to find ways to reduce the capacity ratio in order to increase the number of pipes handled per lift by the manipulator. Two issues are related to this aspect: (1) increasing the lifting capacity and (2) enabling multi-pipe lift. A second aspect is to reduce the cycle time per lift. which involves the design of a better control system than the existing 8 -lever control panel.

\section{A. Reducing the Capacity Ratio}

The first obstacle to reducing the capacity ratio is the limited lifting capacity. With the current configuration, the manipulator's lifting capacity is only 1600 pounds. Since this limitation is mainly imposed by the geometric stability of the system, it may be possible to obtain a higher capacity by enforcing certain arm rnotions with which the moment resulted from the payloud at tine manipulator base is always below a certain amount. This possibility is, however, considered impractical in the field because of the strict safety requirements for construction job sites. Another possibility is to increase the distance between outriggers. This concept is feasible only if the physical strength of every components of the manipulator is examined.

If a higher lifting capacity is obtained, two means are possible to achieve the goal of lifting multiple pipes per lift. One can create an attachment at the end of the manipulator assembly on which to attach a sling. This attachment could be a hook device such as that used on a cherry picker. This device must have the ability to be removed easily prior to actual manipulator use. It is also possible to modify the jaws such that bundled pipes can be grasped and lifted. It is perceivable that with the modified means of handling pipes the crew size may have to increase due $t o$ the same set of reasons for a conventional cherry picker. However, it is quite possible that the productivity of both machines becomes comparative in this configuration.

\section{B. Shortening the Cycle Time}

According to the field productivity data (Table 2), the average cycle time for a maninulator oneration With close examination, it can be seen that this duration does not reflect the actual motion time of the manipulator. Various types of delay exist in the cycle time such as the decision process and the trial-and-error process experienced by an operattor. It may be possible to reduce these delays with the aid of a more friendly control system. To comprehend the anount of delay that can be potentially reduced by a better control system, it is essential to know the actual motion time.

Table 4 is an exhibit of a detailed pipe-handling operation by the manipulator. The manipulator motion data in the first four columns in the table were retrieved by numerous sessions of viewing VCR tape in slow motion. A total of fourteen joint motions are involved in the operation. The maximum joint motion rates and force buildup delay time are obtained from field experiments by one of the authors. Based on these data, 
the actual manipulator motion time is calculated and totaled at 90.14 seconds. Accordingly, 74.86 seconds are attributed to various delays and can possibly be saved by an enhanced control system.

Another opportunity presented by an enhanced control system is the ability to enable the operator to move several joints simultaneously. In the case of handling pipe in a laydown yard, many of the fourteen manipulator joint motions identified in Table 4 can be moved at the same time. For example, the following six segments of motions can be considered:

(1) Segment 1: Swing, Main Telescope, Main Lift, and Main Telescope

(2) Segment 2: Roll, Rotate, Main Lift and Secondary Telescope

(3) Segment 3: Grasp

(4) Segment 4: Main Lift

(5) Segment 5: Swing, Main Lift and Secondary Telescope

(6) Segment 6: Release

Table 4 A Detailed Analysis of a Pipe Handling Operation by the Manipulator (in seconds)

\begin{tabular}{|c|c|c|c|c|c|c|c|}
\hline Manipulator Motions & Type & Unit & $\begin{array}{l}\text { Motion } \\
\text { Range }\end{array}$ & $\begin{array}{c}\text { Maximum Joint } \\
\text { Motion Rate }\end{array}$ & $\begin{array}{c}\text { Rate } \\
\text { Reduction }\end{array}$ & $\begin{array}{c}\text { Force Buildup } \\
\text { Delay } \\
\end{array}$ & $\begin{array}{c}\text { Motion } \\
\text { Time } \\
\end{array}$ \\
\hline Swing Base & C. Clockwise & $\operatorname{deg}$ & 90 & $19.8 \mathrm{deg} / \mathrm{sec}$ & & 0 & 4.54 \\
\hline Main Telescope & Out & Inch & 24 & $10.7 \mathrm{inch} / \mathrm{sec}$ & & 0 & 2.24 \\
\hline Main Lift & Up & $\operatorname{deg}$ & 30 & $4.6 \mathrm{deg} / \mathrm{sec}$ & & 0 & 6.52 \\
\hline Main Telescope & Out & Inch & 36 & $10.7 \mathrm{inch} / \mathrm{sec}$ & & 0 & 3.36 \\
\hline Gripper Roll & Down & $\operatorname{deg}$ & 15 & $32 \mathrm{deg} / \mathrm{sec}$ & $50 \%$ & 1 & 1.94 \\
\hline Gripper Rotate & Clockwise & $\operatorname{deg}$ & 5 & $13 \mathrm{deg} / \mathrm{sec}$ & $50 \%$ & 3 & 3.77 \\
\hline Main Lift & Down & $\operatorname{deg}$ & 10 & $4.6 \mathrm{deg} / \mathrm{sec}$ & $50 \%$ & 0 & 4.35 \\
\hline Secondary Telescope & Out & Inch & 5 & $1.4-1.5 \mathrm{inch} / \mathrm{sec}^{*}$ & $50 \%$ & 1.5 & 8.64 \\
\hline Gripper Grasp & Close & Cycle & & 8 seconds/cycle & & 1 & 8 \\
\hline Main Lift & Up & deg & 45 & $4.6 \mathrm{deg} / \mathrm{sec}$ & & 0 & 9.78 \\
\hline Swing Base & Clock-wise & deg & 90 & $19.8 \mathrm{deg} / \mathrm{sec}$ & & 0 & 4.54 \\
\hline Main Lift & Down & deg & 55 & $4.6 \mathrm{deg} / \mathrm{sec}$ & & 0 & 11.96 \\
\hline Secondary Telescope & Out & Inch & 7 & $1.4 \mathrm{inch} / \mathrm{sec}$ & $50 \%$ & 1.5 & 11.5 \\
\hline Gripper Release & Open & Cycle & & 7 seconds/cycle & & 1 & 9 \\
\hline \multicolumn{6}{|c|}{ * Telescope-in: $1.5 \mathrm{inch} / \mathrm{sec}$, Telescope-out: $1.4 \mathrm{inch} / \mathrm{sec}$} & Total & 90.14 \\
\hline
\end{tabular}

Since several joint motions can move simultaneously, the motion time for each segment is the longest joint motion time within that segment. Consequently, the total cycle time is further reduced from 90.14 seconds to 53.9 seconds (Table 5). With the shortened cycle time, the relationship between the capacity ratio and the crew size ratio has been recalculated and is depicted in Figure 4. Comparing the figure with Figure 3 , it can be seen that the "Manipulator Region" is greatly increased, indicating that an enhanced manipulator will be more productive than a cherry picker in most cases.

Table 5 Reduced Manipulator Cycle Time

\begin{tabular}{cc}
\hline Motion Segment & Motion Time (seconds) \\
\hline Segment 1 & 6.52 \\
Segment 2 & 8.64 \\
Segment 3 & 8 \\
Segment 4 & 9.78 \\
Segment 5 & 11.96 \\
Segment 6 & 9 \\
\hline Total & 53.9 \\
\hline
\end{tabular}




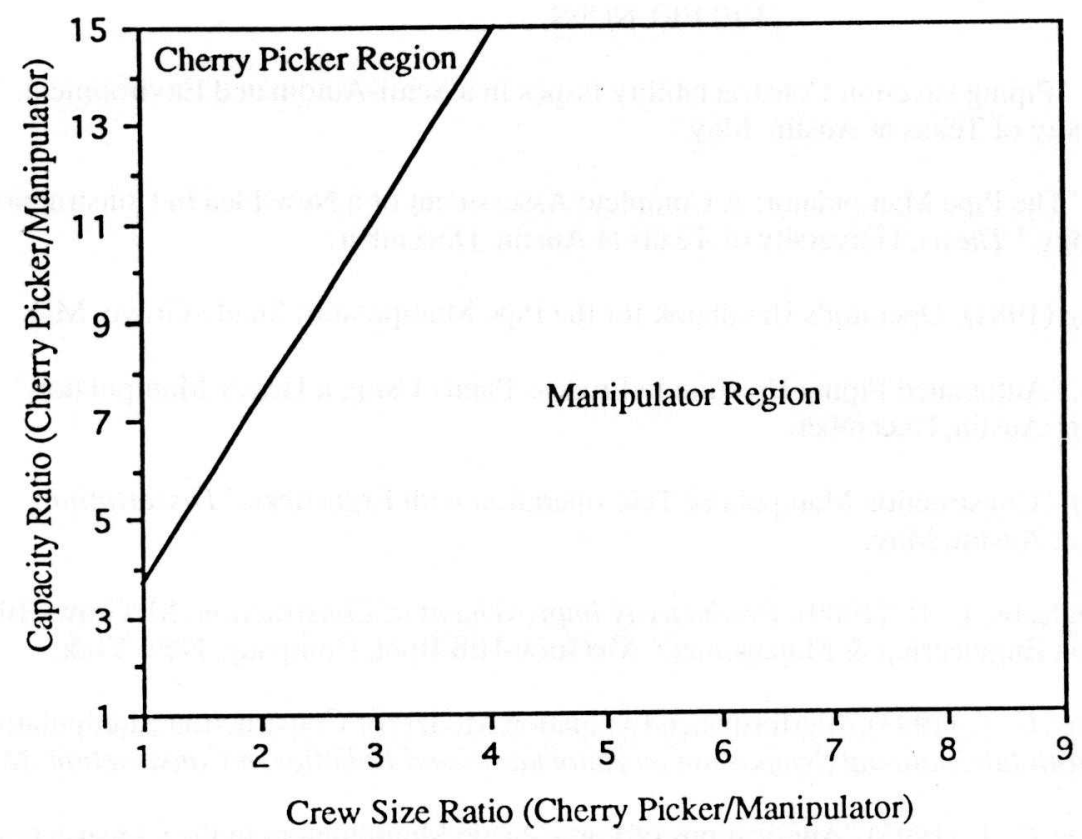

Figure 4 Sensitivity Analysis with A Better Manipulator Control System

\section{CONCLUSIONS}

This paper has presented the results of a field study that involves the productivity comparison of a telescopic rough terrain crane and a prototype pipe manipulator. With the manipulator's current capabilities, the cherry picker outperforms the manipulator by a ratio of 5.16:1 in terms of total work-hours, whereas the manipulator has a slightly shorter cycle time of 165 seconds as opposed to the cherry picker's 198 seconds.

Nevertheless, an underestimated benefit of the pipe manipulator is its promising safety improvement. Improved safety is gained by reducing the labor employment and removing workers from physically interacting with pipes. The major problem areas of the prototype manipulator found in this study are the limited lifting capacity, single-pipe lift restriction and the difficult 8-lever control system with which an operator generally has problems moving more than two joints at the same time. With these problems, it is highly unlikely that constructors will be interested in using the manipulator for handling pipes.

The failure of the pipe manipulator, in its current configuration, to compete with a cherry picker signifies the need for more research. Two major areas for improvement discussed in this context are the feasibility of multi-pipe lift and the design of an enhanced control system. Both areas have shown very high potential, in that the multi-pipe lift will enable the pipe manipulator to be readily competitive to a cherry picker, and a better control system has the potential to shorten the cycle time from 165 seconds to 53.9 seconds, a reduction of $67 \%$. With these enhancements, the pipe manipulator may become a much better piece of equipment than a cherry picker in handling pipes.

\section{ACKNOWLEDGEMENT}

We would like to acknowledge Head \& Guild Equipment Co. and Dow Chemical Co. for their support of this research project. 


\section{REFERENCES}

1. Fisher, D. J. (1989). "Piping Erection Constructability Issues in a Semi-Automated Environment." Dissertation, University of Texas at Austin, May.

2. Glass, C. C. (1984). "The Pipe Manipulator: A Complete Assessment of a New Idea in Construction Equipment Technology." Thesis, University of Texas at Austin, December.

3. Grove Manufacturing (1981,). Operator's Handbook for the Pipe Manipulator, Shady Grove, MD.

4. Hughes, P. J. (1987). "Automated Piping Erection in Process Plants Using a Heavy Manipulator." Thesis, University of Texas at Austin, December.

5. Hughes, P. J . (1990). "Construction Manipulator Tele-operation with Ergosticks." Dissertation, University of Texas at Austin, May.

6. Parker, H. W. and Oglesby, C. H. (1989). Productivity Improvement in Construction, McGraw-Hill Series in Construction Engineering \& Management, McGraw-Hill Book Company, New York.

7. Hsieh, T. Y. and Haas, C. T. (1993). "Performance Evaluation Model for Construction Manipulators." Proceedings of the 10th International Symposium on Automution and Robotics in Construction, May.

8. Hsieh, T. Y. and Haas, C. T. (1993) "Applications of Large-Scale Manipulators in the Construction Environment." Proceedings of the 10th International Symposium on Automation and Robotics in Construction, May. 